Supporting Information

\title{
Scanning Electrochemical Microscopy. 56. Probing Outside and Inside Single Giant Liposomes Containing Ru(bpy) ${ }_{3}{ }^{2+}$
}

Wei Zhan and Allen J. Bard*

Department of Chemistry and Biochemistry, University of Texas, 1 University Station, A5300, Austin, Texas 78712

Three approach curves of tip breaking into liposomes filled with Ru(bpy) ${ }_{3}{ }^{2+}$ (as the case illustrated in Fig. 6 (A)) are shown in the following.
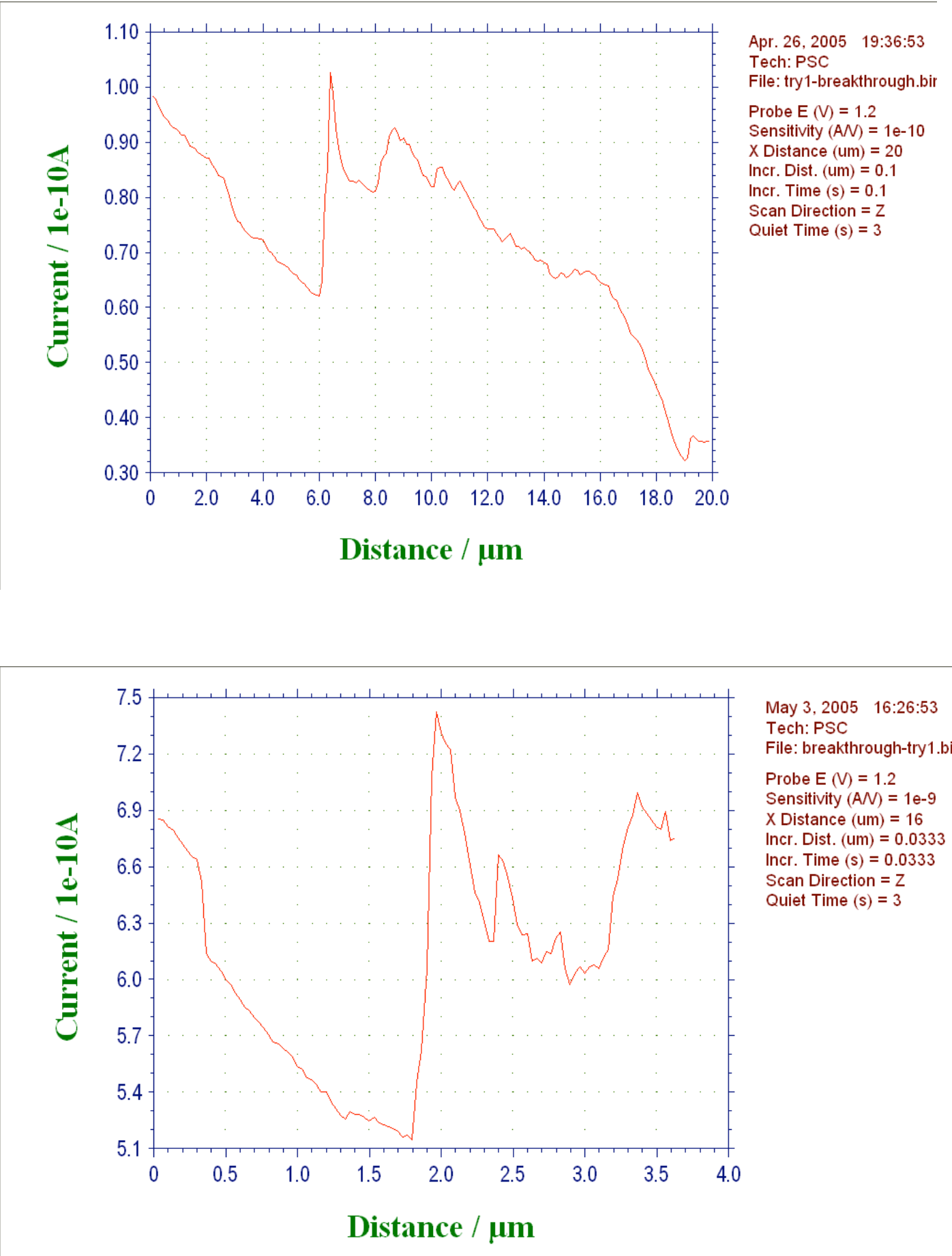

May 3, 2005 16:26:53

Tech: PSC

File: breakthrough-try1.bir

Probe $E(V)=1.2$

Sensitivity $(A N)=1 e-9$

$\mathrm{X}$ Distance $(\mathrm{um})=16$

Incr. Dist. $($ um $)=0.0333$

Incr. Time $(s)=0.0333$

Scan Direction $=\mathbf{Z}$

Quiet Time (s) $=3$

Distance / $\mu \mathrm{m}$ 


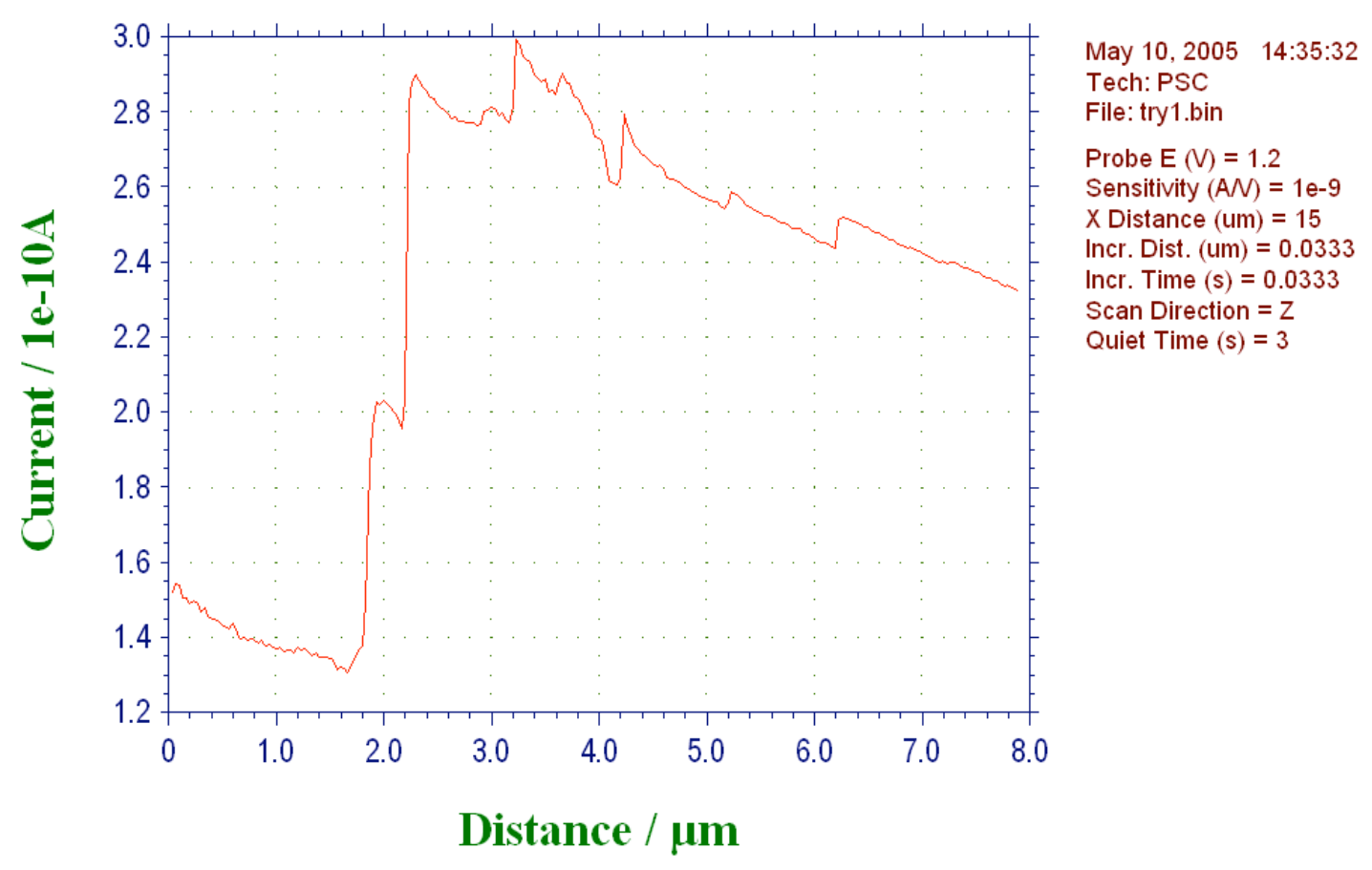

